\title{
Economic impact of ischemic heart diseases in Brazil: comparison through the input-output matrix to the years 2006 and 2014
}

\section{Impacto econômico das doenças isquêmicas do coração no Brasil: comparação através da matriz insumo-produto para os anos 2006 e 2014}

\author{
Henry Ledur Paz Cezar ${ }^{1}$ \\ Orcid: http://orcid.org/0000-0002-1043-4414
}

\author{
Everlam Elias Montibeler ${ }^{2}$ \\ Orcid: http://orcid.org/0000-0001-8899-8669
}

\author{
Daniel Rodrigues Cordeiro ${ }^{3}$ \\ Orcid: http://orcid.org/0000-0002-3127-7083
}

\begin{abstract}
The purpose of the article was to measure the impacts caused by Ischemic Heart Diseases (IHD) on Brazilian GDP in 2006 and 2014. The effects of IHD were Universidade Iguaçu UNIG by applying shocks applied to 56 sectors, in current values of the impact on income. The method used included information on the Disability Adjusted Life Years (DALY), developed by the World Health Organization (WHO) through the study of Global Illness Burden; and Leontief Inverse. The results showed that the direct impacts of the IHD on GDP in 2006 were approximately US\$ 166 million and US\$ 362 million in 2014, and direct and indirect impacts were US\$ 800 million in 2006 and US\$ 1.3 billion in 2014. The total economic impact exceeded those of US\$ 919 million in 2006 and US\$ 1.7 billion in 2014.
\end{abstract}

Keywords: IHD. GPD. DALY. Leontief.

\section{Resumo}

O objetivo do artigo foi mensurar os impactos causados pelas Doenças Isquêmicas do Coração (DIC) sobre o PIB brasileiro em 2006 e 2014. Os efeitos das DIC foram avaliados mediante choques de demandas aplicados sobre 56 setores, condicionando a realização da estimação em valores correntes do impacto sobre a renda. O método utilizado contou com as informações dos Perda de Anos de Vida Ajustados (DALY) por incapacidade, desenvolvido pela Organização Mundial da Saúde (OMS) através do estudo de Carga Global de Doença; e a Inversa de Leontief. Os resultados mostraram que os impactos diretos das DIC sobre PIB de 2006 foram de aproximadamente US\$ 166 milhões e de US\$ 362 milhões em 2014, já os impactos diretos e indiretos foram de US\$ 800 milhões em 2006 e US\$ 1.3 bilhão em 2014. O impacto econômico total ultrapassou os de US\$ 919 milhões em 2006 e US\$ 1.7 bilhão em 2014.

Palavras-Chave: DIC. PIB. DALY. Leontief.

\footnotetext{
${ }^{1}$ Universidade Federal do Rio de Janeiro - UFRJ, Brasil. E-mail: henryledur7@gmail.com

${ }^{2}$ Universidade Federal Rural do Rio de Janeiro - UFRRJ, Brasil. E-mail: everlamelias@gmail.com

${ }^{3}$ Universidade Iguaçu - UNIG , Brasil. E-mail: danielrodriguesco@gmail.com
} 


\section{INTRODUCTION}

Ischemic Heart Diseases (IHD) are currently the leading causes of death in the world, it is estimated that 17.7 million people died from cardiovascular disease in 2015, accounting for $31 \%$ of all deaths globally (PAHO, 2017). They constitute the most prominent pathologies of the Cardiovascular Diseases Group, and only in Brazil there were 807,304 clinical hospitalizations in the year of 2015 . The average cost with consultations and hospitalizations exceeded US\$ 1.3 billion to the same year (SIQUEIRA; SIQUEIRAFILHO; LAND, 2017).

The economic costs made by the impacts of Ischemic Cardiopathy or Coronary Artery Disease are consequence both mortality and morbidity indicators. The concept of Disability Adjusted Life Years (DALY) was developed collaboratively between the World Health Organization and the World Bank at the end of the last century. DALY is an indicator capable of showing the health level of the population of a country, combining mortality and morbidity data, also allowing classification by gender, geographic area, age and social status: Disability Adjusted Life Years (DALY), one DALY is equal one year of healthy life lost (IHME, 2013).

Data analysis using DALYs provides an understanding not only of the number of deaths in each country or continent, but also the impact of premature deaths and the disability or disability of the population, which combined provide the socalled Global Disease Burden (GDB), where the influence of each condition on the total number of DALYs in the study region (MURRAY; LOPEZ, 1996).

Ischemic Cardiopathy, as well as other non-communicable chronic diseases, presents as a multifactorial disorder multiple factors are determinant for its development (PAHO, 2017). In addition to the traditional risk factors, such as lack of physical activities, smoking, harmful use of alcohol and inadequate diet, the socioeconomic conditions in which the individual is inserted also exert an influence on the occurrence of the disease, with the Gross Domestic Product (GDP) inversely related to its development (TURA; SILVA; PEREIRA, 2006).

Because of their influence on the health status of Brazilians and their upheavals in the national economy, IHDs are pathologies that demand attention from government officials, who, through credible data that have an impact on society and the country's economy, can develop public health policies, operating in the purpose of reducing the incidence of these pathologies, providing a higher quality of life to the population. We sought to understand in this paper, therefore, how Ischemic Cardiopathy affects the economy of the country and which sectors are most impacted by the disease.

Based on the information presented, this work was oriented to measure the economic impact of Ischemic Heart Diseases in Brazil to the years 2006 and 2014, estimating the effects on the product, workers' wages and productive sectors of the Brazilian's economy, making a comparison of the impacts between both periods.

On the context of government planning, aiming at greater health service efficiency, this research was justified by generating useful information to the public policy makers in the health field, evidencing the effect of the IHD on Brazilian's GDP and in Input-Output Matrix, creating the conditions to investments in prevention in these sectors to be more efficient.

The present work was based on information from Brazilian's Input-Output Matrix to the years 2006 and 2014 made available by World Input-Output Database (WIOD - http://www.wiod.org/home). The effects of IHD were evaluated through the impact of compensation on demand, which allowed the estimation of the impact on GDP. These shocks were realized from the application of the concept of Inoperability 
of the Input-Output model, developed by Haimes and Jing (2001) through the Leontief (1951), allowing the measurement of the degree of degradation caused by IHD in each economic sector.

\section{THEORETIC BACKGROUND}

Cardiovascular diseases and ischemic heart diseases

The major Non-Communicable Chronic Diseases (NCCDs) have been responsible to a large proportion of deaths occurring before the age of 70 , resulting in disability and leading to a high degree of limitation of sick people in their work and leisure activities, increasing the pressure on public health services (SCHMIDT et al., 2011).

Heart Diseases or Cardiovascular Diseases (CDs), occupy the first position as the cause of death among the NCCDs. In 20th century, less than $10 \%$ of deaths worldwide were attributed to CDs, however, in the beginning of the $21 \mathrm{st}$ century CDs caused nearly $50 \%$ of deaths in developed countries, and $25 \%$ in developing countries (FONSECA, 2013).

According to the data of the National Health Survey (NHS, 2013), 6.1 million people over the age of 18 reported having had a medical diagnosis indicating some heart disease in Brazil, the percentage of the urban area being equivalent to $4.4 \%$ of the total population, $3.3 \%$ higher than the rural area. Heart Diseases have, historically, the main risk factors are hypertension, smoking, high cholesterol, obesity, harmful eating habits and sedentary lifestyle (MACHADO, 2006). IHDs rank first in causes of death, especially premature deaths, being responsible for $17.33 \%$ of the world's total deaths (IHME, 2018).

Ischemic heart disease affects the arteries of the heart through the formation of fatty plaques in the coronary artery, compromising the circulation and causing ischemia, which is the decrease of nutrients and oxygen to the muscles of the heart, leading to pain or discomfort in the chest, heart palpitations, shortness of breath and tiredness because a part of the heart does not receive enough blood to pump properly (NCI, 2004).

Ischemic Heart Diseases occupied, according to information of PAHO (2017), the first position as the cause of death among nations with high income, among which Brazil is, killing 140 per 100,000 people only in 2016. Diseases in Brazil are divided according to the International Classification of Diseases and Related Health Problems, often called ICD. They provide codes relating to the classification of diseases and a wide variety of signs, symptoms, abnormalities, complaints and other circumstances relating to injury or illness.

Between 2005 and 2016 there was a $22.6 \%$ increase in the total number of deaths due to Ischemic Cardiopathy in Brazil. Data from the Institute of Health Metrics and Evaluation (IHME, 2017) demonstrated that there was a $15.7 \%$ increase in the causes of premature deaths due to Ischemic Heart Diseases, making these diseases the first place in the ranking of the main causes of death, followed by interpersonal violence, traffic accidents and stroke.

The morbidity caused by Cardiovascular Diseases represents a burden to the public health system in countries around the world. Townsend et al. (2015), showed that the rate of hospitalization to these diseases has been increasing in Europe since the turn of the century, with more countries with records of increased hospital admissions (34 countries) than countries with decreasing admission records (15 countries) by CDs.

The numbers of hospitalization authorizations for IHD in Brazil, considering people of both sexes and of all ages, also denote the increase in morbidity due to this group of pathologies in the country. According to the data extracted by the information system DATASUS (2008), the number of hospital admissions to IHD was of the order of 208,176 , representing a 
cost of just over US\$ 197 million and totaling 1,340,793 days of stay in public and private hospitals that had ties with the Health Unic System (HUS), also known in Brazil under the acronym SUS. When compared to the data for 2014, it is possible to observe an increase of approximately $22 \%$ in the number of authorizations for hospital admissions $(253,834$ in 2014), of which US\$ 437,551,501.27 is the hospitalization cost for that year, with an increase of $22.3 \%$ in the number of days spent in hospitals.

Government expenditure on public health

Most countries suffer from the accelerated growth of public debt, with health spending being one of the most important. One of the major developments faced by the Brazilian state is to ensure the long-term sustainable functioning of a free, universal public health system, without raising public spending. In order to reduce public debt, it is important that in addition to reducing spending on patient care, minimize lost work days. The fall in income affects GDP and consequently the denominator of the debt ratio that is determined by the expenditure/revenue ratio.

According to the date of Health Satellite Account, an extension of the System of National Accounts (SNC) published by the Brazilian Institute of Geography and Statistics (BIGS), also known as IBGE in Brazil, in the year 2015 the final consumption of health goods and services in Brazil was US\$ 140 billion, which represented $9.1 \%$ of the Gross Domestic Product (GDP) of that year. Of this amount, the Government's consumption expenditure was equal to US\$ 59 billion (3.1\% of GDP) and the others US\$ 81 billion was charged to consumption by households and non-profit institutions serving households (IBGE, 2017). Cardiovascular Diseases in Brazil, according to data from the System Information Health of SUS (SIH/SUS,
2018), were responsible for $1,130,962$ hospitalizations in public and private hospitals, costing approximately US\$ 616 million only in 2017.

Studies carried out over the last decade have shown how GDP has been impacted by some chronic diseases. Rasmussen, Sweeny, and Sheehan (2015) observed that chronic non-communicable diseases have been responsible for a negative impact on the Brazilian's economy, projecting an estimated of 5.8\% from the Gross Domestic Product loss for 2030, which would be equivalent to US\$ 184 billion of losses in the public coffers. The same study showed that the number of people over 45 in the Brazilian's workforce doubled from $15 \%$ in 1980 to $30 \%$ in 2015 , with a forecast of $38 \%$ for the year 2030 , which importance of assessing the impact of IHD on the country's productivity.

Tura, Silva and Pereira (2006), analysis of the time series of GDP per capita between 1947 and 2004 and IHD's mortality between 1980 and 2002, found a correlation of -0.68 for males and -0.55 for females, 20-year lag between the series, it means', IHD mortality in 2004 is associated with per capita GDP in 1984. The same study concluded that per capita GDP would correlate over the same 20 -year period with $30.3 \%$ of the number of deaths in women and $46.2 \%$ for men, which creates strong evidence that GDP per capita can be considered one of the main risk factors for ischemic heart disease, with even greater participation than classic factors: gender, age, family history, diabetes mellitus, hypertension, smoking, sedentary lifestyle, among others.

Cost-benefit evaluation in public health is an important tool for decisionmaking in health-related policies. The economic impacts of population health can be evaluated using indicators of mortality and morbidity, as these reflect the costs that are directly linked to a specific condition, such as lost productivity measured by days of work lost, premature death and medical expenses, such as treatments, 
hospitalizations, exams and medicines (DRUMMOND, SCULPHER \& TORRANCE, 2006).

\section{Disability adjusted life of years (Daly)}

The analysis of health conditions through the Global Disease Burden (GDB), provides comprehensive information on some of the major diseases. The GDB is measured by the indicator DALY, which in turn comprises the mortality indicator Years of Life Lost (YLL), plus the disability indicator Years Lost due to Disability (YLD).

\section{$\mathrm{DALY}=\mathrm{YLL}+\mathrm{YDL}$}

The indicator DALY, which combines mortality and morbidity, has proved to be an efficient tool to analyzing the effect generated in the economy, caused by diseases and other conditions that lead to poor health. The causes that generate DALY can be understood according to their importance in the economy of a country, as shown Costa and Guilhoto (2014), where they use DALYs as a method to measure the economic impact of the installation of sewage digesters in Brazilian's rural households, showing that a government budget savings of US\$ 55 million would be realized, considering only the number of children who would no longer use public health services for treatment of diseases due to sanitary conditions related to the ideal treatment of sewage.

The analysis of data through the use of DALYs provides an understanding not only of the number of deaths in each country or continent, but also the impact of premature deaths and the disability or disability of the population, which together provide the GDB, where the influence of each pathological condition in the total number of DALYs of the study region (MURRAY; LOPEZ, 1996). This indicator also makes it possible to identify the causes that imply the greatest lack of health for the population, making it possible to classify the diseases or diseases that impact on the health condition of the population of each country, and also have flexible mechanisms that allow the updating of annual data. The DALY combines information on mortality and morbidity, constituting an essential tool for measuring and reducing the incidence of the disease (LEITE et al., 2015). One unit of DALY it is equal one year of lost healthy life (IHME, 2013). According to Marinho, Passos and França (2016, p. 714), the importance of the GDB has grown every year, in order to create frameworks for health actions:

\begin{abstract}
Analyzes of disease burden are important to the elaboration of indicators that subsidize the planning, execution and evaluation of health actions. Traditional analyzes, made for each disease separately, may present inconsistencies, such as the sum of causes deaths exceeding total mortality.
\end{abstract}

Studies of Ischemic Heart Diseases, based on analyzes related to the burden of Global Illness, allow more precise assessments of the consequences of these diseases in Brazil, which contributes to the understanding of how they can impact economically in the country, exerting influence in the level of government spending, wages and consumption of economic agents.

Disability Adjusted Life of Years by Incapacity are introduced in the inputoutput tables as a vector of reduction of the number of working hours, thus generating a reduction in the sectoral and global wage mass, which in turn impacts on consumption. The disturbance of the demand causes the increase in the difference between planned and degraded production.

\section{METHOD}

Input-output model

The Input-Output Matrix is a model constructed from data observed in a given 
economy, which may be a region or other delimited area that allows the observation of the interrelationships between sectors and industries (MILLER; BLAIR, 2009).

To Leontief (1951), the InputOutput Matrix allows a clear description of how sectors of the economy interact with each other considering a given time period and region. According to Guilhoto (2001, p. 11), Leontief developed a model capable of equating demand and supply within a network of multiple activities, where it showed the interactions between them:

What Leontief was able to accomplish was the construction of an "economical photograph" of the economy itself; in this photograph he showed how sectors are related to each other - that is, which sectors supply the others with services and products and which sectors buy from whom. The result was a unique and comprehensive view of how the economy works - how each sector becomes more or less dependent on others.

The input-output model enables the understanding of the product flows between the segments of an economy to a given period of time, evidencing the relationship between producers and consumers, as well as providing the interrelationship between the sectors that demand and offer inputs (TAKASAGO et al., 2017). It is an adaptation of the neoclassical theory of general equilibrium and it is described by a set of linear equations in which the ultimate goal is to estimate the economic impacts of a given system (LEONTIEF, 1951).

The approach used in the present study was based on Leontief (1951), where, the total gross output throughout the economy ( $\mathrm{x}$ ) is taken to be the sum of the production by Matrix that is destined for the various sectors for intermediate consumption $(Z)$, which is demanded by the final consumers, denoted by the variable $(y)$ as described by the Equation (1):

$$
\mathrm{x}=\mathrm{Z}+\mathrm{y}
$$

The Equation (1) can be represented in a matrix form of technical coefficients (A), also known as a matrix of direct coefficients, as described below in the Equation (2):

$$
\mathrm{A}=\mathrm{Z} * \hat{\mathrm{X}}^{-1}
$$

Where the $\hat{\mathrm{x}}$ is vector denotes a diagonal matrix with the elements of the vector along the main diagonal. In the Input-Output model, the transactions in the economy are made considering two sectors, a vendor or supplier, which can be indicated by the subscript $i$ and a buyer sector, represented by the subscript $j$. Thus, relating each sale from the supplier sector to the buyer sector of matrix (Z), with the gross value of the production of the buyer sector $(\mathrm{x})$, we will get what is known as technical coefficient (a), obtained from the ratio of the variables presented. This technical coefficient can best be visualized by the following Equation (3):

$$
\mathrm{a}=\mathrm{Z} / \mathrm{x}
$$

Where each coefficient represents the required quantity of sector inputs $i$ to produce a unity of good (output) $j$. The model also assumes that there is direct proportionality between the gross production of the sector $j$ and the total amount of inputs it acquires from other suppliers. From this assumption, it is understood that the technical coefficients (a) are constant, which creates a framework to obtain the Equation (4):

$$
\mathrm{Z}=\mathrm{a} * \mathrm{X}
$$

Equation (4) shows that the purchases that a sector $j$ effect of another particular sector $i$ is calculated by multiplying the gross value of the output of this buyer sector by a constant coefficient (a). The matrix of technical coefficients is better visualized in Equation (5): 


$$
\mathrm{A}=\left[\begin{array}{ccc}
\mathrm{a} 11 & \cdots & \mathrm{a} 1 \mathrm{j} \\
\vdots & \ddots & \vdots \\
\text { ail } & \cdots & \text { aij }
\end{array}\right]
$$

The Equation (5) the main diagonal denotes the intrasectorial technical coefficients, while the secondary diagonal presents the intersectoral direct coefficients. Equation (6):

$$
\mathrm{Ax}+\mathrm{y}=\mathrm{x}
$$

Through the Equation (6) it becomes possible to obtain the total output that is needed to satisfy the final demand. Solving Equation (6), we arrive at the Equation (7):

$$
\mathrm{x}=(\mathrm{I}-\mathrm{A})^{-1} * \mathrm{y}
$$

The matrix $(I-A)$ is called the Leontief Matrix, and $(\mathrm{I}-\mathrm{A})^{-1}$ is called the Leontief Inverse Matrix. Through the Inverse of Leontief would be possible to calculate the production values $(\mathrm{x})$ just by multiplying the inverse by the final demand, which creates the possibility of estimating the product in a simple way.

The tool developed by Leontief allows the understanding of how the sectors of the economy interact directly and indirectly in order to produce their final product. From this model, various analyzes can be carried out, such as the measurement of the impacts of the variation of the demand on the product, quantity of jobs generated, added value, among others (MARCONI; ROCHA; MAGACHO, 2016).

Inoperability input-output model (IIM)

Searching the understanding of how a sector or group of sectors can be negatively or positively affected by external shocks, the concept of Inoperability of the Input-Output model assumes an important role. Based on the model improved by Leontief (1951), the IIM is defined as the inability of a system to perform its intended functions, denotes the level of system dysfunction, expressed as a percentage of the level of production desired by such a system. Intended to predict, through this concept, the result of economic losses suffered by individual sectors, which in turn is the result of a direct rupture with a particular sector or a group of sectors (SANTOS, 2012). Developed by Haimes e Jing (2001), from work of Leontief (1951), the inoperability formulation of the inputoutput model can be represented in Equation (8):

$$
\mathrm{q}=\mathrm{A}^{*} \mathrm{q}+\mathrm{c}^{*}
$$

Where (q) is constituted as the vector of Inoperability given in terms of normalized economic losses, $\left(\mathrm{A}^{*}\right)$ is the matrix of interdependence and $\left(\mathrm{c}^{*}\right)$ is the demand disturbance, measured as a consequence of the difference in projected demand and degraded demand, which in this case will be one that was disturbed due to absenteeism in the work generated by the IHD.

Details of derivation of Inoperability of the Input-Product model can be found in the work of Santos (2012), in which an analysis of interdependence is performed valuing the reduction of demand through the concept of Inoperability. Santos e Haimes (2004), where demand reduction modeling is carried out through the IIM caused by terrorism and in Leung, Haimes e Santos (2007) which aims to present two perspectives: one on the supply side and the other on the product side, in order to complement and supplement the demand directed in the Inoperability Matrix of the Input-Output Matrix.

The equilibrium presented by Equation (8) can also be evidenced by the understanding that Inoperability is defined as the degraded and normalized lost production of the sector $i$, where $\left(\mathrm{q}_{\mathrm{i}}\right)$ is demonstrated in Equation (9):

$$
\mathrm{q}_{\mathrm{i}}=\hat{\mathrm{x}}_{\mathrm{i}}-\left(\tilde{\mathrm{x}}_{\mathrm{i}} / \hat{\mathrm{x}}_{\mathrm{i}}\right)
$$


Where $\left(\hat{\mathrm{x}}_{\mathrm{i}}\right)$ is the planned production level and $\left(\tilde{\mathrm{x}}_{i}\right)$ is the value of the degraded production after a shock suffered. The value to be found by Equation (10):

$$
0<=\text { qi }<=1
$$

The interval in Equation (10) has the meaning that when the $\left(\mathrm{q}_{\mathrm{i}}\right)$ is equal to 0 , there is no disturbance in the economy and when it is equal to 1 , the production was completely degraded due to the labor shortages by Coronary Artery Disease. Still further from Equation (8), two other auxiliary values can be obtained:

$$
\begin{aligned}
& \mathrm{c}^{*}=\hat{\mathrm{x}}^{-1} *(\mathrm{c}-\mathrm{d}) \\
& \mathrm{A}^{*}=\hat{\mathrm{x}}^{-1} *\left(\mathrm{~A}^{*} \hat{\mathrm{x}}\right)
\end{aligned}
$$

Where $\left(\mathrm{c}^{*}\right)$ is the variable that represents the demand disturbance and (c) is the final demand planned, being (d) given by demand degraded by the impact of the IHD on the workers.

Another auxiliary value obtained through the inoperability model equation of the product input in Equation (8) is the reference matrix of interdependence $\left(\mathrm{A}^{*}\right)$, expressed as a function of the planned demand level and the direct coefficient matrix.

\section{ECONOMIC IMPACT OF CARDIOVASCULAR DISEASES AND ISCHEMIC HEART DISEASES}

Aiming to carry out a work in accordance with the numbers of the national workforce, it was sought to measure the quantities of workers and their salaries received monthly by sector from the Annual Report of Social Information (ARSI, also known as RAIS in Brazil http://bi.mte.gov.br/bgcaged/login.php).

ARSI is an important data collection instrument developed and updated by the government management to provide data for the preparation of labor statistics and to activities in the country. Using National Classification of Economic Activities (NCEA), provided by IBGE. ARSI presents annual data to 87 productive sectors, with information on quantity of workers, and the data can be filtered, as in the present study, according to the number of minimum wages received, which categorize workers who receive from half a minimum wage to workers who are framed in more than 20 minimum wages. The tables to the years 2006 and 2014 were used, and the data were presented according to version 2.0 of NCEA. The classifications of the economic sectors present in the tables provided by the ARSI were harmonized with the classifications available through the WIOD tab*les, since they have 31 more classifications than this one.

To both years (2006 and 2014), the direct impact on GDP was measured by lost wages. As the indicators of the ARSI account for the number of workers per minimum wage, the minimum wage was used for each year, namely: US\$ 160.89 in 2006 and US\$ 307.62, which was the effective January 1, 2014. The impacts mentioned, both of minimum wages lost, as well as of GDP and the sectoral economic losses are expressed in current values of the studied times. The total impact, as a result of the direct and indirect effect, was measured by the sum of the economic loss of each sector. To a better measurement of economic losses, it was necessary to withdraw $23,26,35,42,43,48,49,55$ e 56 , because the values were zero.

\section{Economic impact of ICDS in 2006}

The economic impact of IHD can be given by how much public sector expends to cope with the morbidity generated by this group of pathologies. According to Table 1, in 2006, Ischemic Cardiopathy led to a total of 208,176 hospitalizations in public and private hospitals linked to SUS. It totaled $1,340,793$ hospitalization days, costing US\$ $213,505,120.41$. 
Table 1 - Number of hospital admissions, total values and days of stay per year, caused by IHD

\begin{tabular}{|c|c|c|c|}
\hline Year & $\begin{array}{c}\mathrm{N}^{0} \text { of } \\
\text { hospitalizations }\end{array}$ & Amount & Days of stay \\
\hline 2006 & 208,176 & US\$213,505,120.41 & $1,340,793$ \\
\hline 2007 & 213,311 & US\$259,184,351.25 & $1,370,063$ \\
\hline 2008 & 195,450 & US\$318,821,239.13 & $1,290,483$ \\
\hline 2009 & 210,046 & US\$350,256,186.68 & $1,385,065$ \\
\hline 2010 & 221,898 & US\$430,042,316.09 & $1,436,955$ \\
\hline 2011 & 231,361 & US\$532,749,312.45 & $1,495,134$ \\
\hline 2012 & 242,858 & US\$488,802,901.93 & $1,571,170$ \\
\hline 2013 & 243,195 & US\$452,702,972.65 & $1,559,205$ \\
\hline 2014 & 253,834 & US\$437,551,501.27 & $1,640,937$ \\
\hline
\end{tabular}

In addition to public expenditure on hospitalizations, the effects of these diseases can be estimated according to their impact on the absenteeism of workers in the productive sectors of the economy. Based on the assumption that absence from work leads to a loss of wages, it is possible to estimate the loss in terms of workers' compensation. Look to Figures 1 and 2.

Figure 1 - Salaries lost in 2006 from Ischemic Heart Diseases

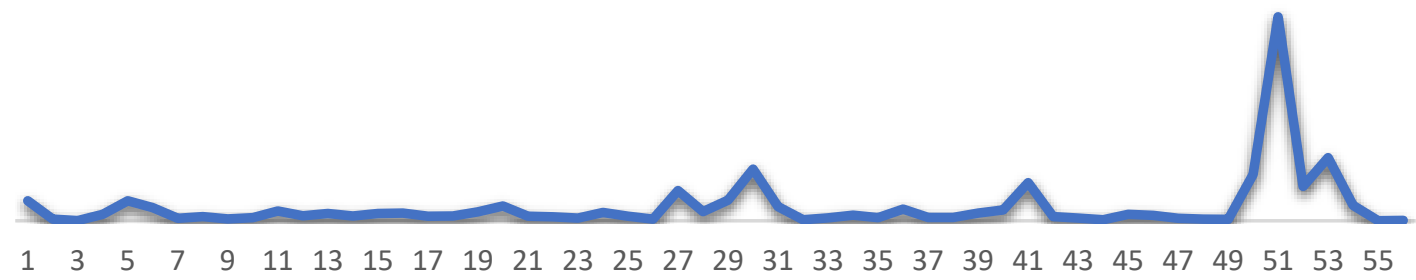

Source: Prepared by authors.

The sector that presented the highest salary loss due to the disease in 2006 was sector 51, which refers to public administration, defense and social security, registering a total of US\$ 43,795,988.89, referring to the sum of lost wages of workers allocated in this sector. Then, sector 53 appears, which includes human health care activities; human health care integrated with social assistance provided in collective and private residences and social assistance services without accommodation, with wage loss accounted in US\$ $13,536,556.17$. In the third position, as most affected in terms of wages, there is sector 30 , referring to retail trade, with losses of US\$ 11,109,293.80. The sector with the lowest wage loss was sector 55, which concerns domestic services, with losses added up in US\$ 17,765.80.

The direct impact on GDP, measured in terms of salary losses to the year 2006, was US\$ $165,903,042.64$. In addition to the impact on society and people's lifestyle, the estimation of the direct impact on the economy reaching the level of more than US\$ 165 million, at the time, indicates the economic detrimental power of the group of pathologies that make up the IHD. 
Figure 2 - Economic loss, in US\$, by sector in 2006

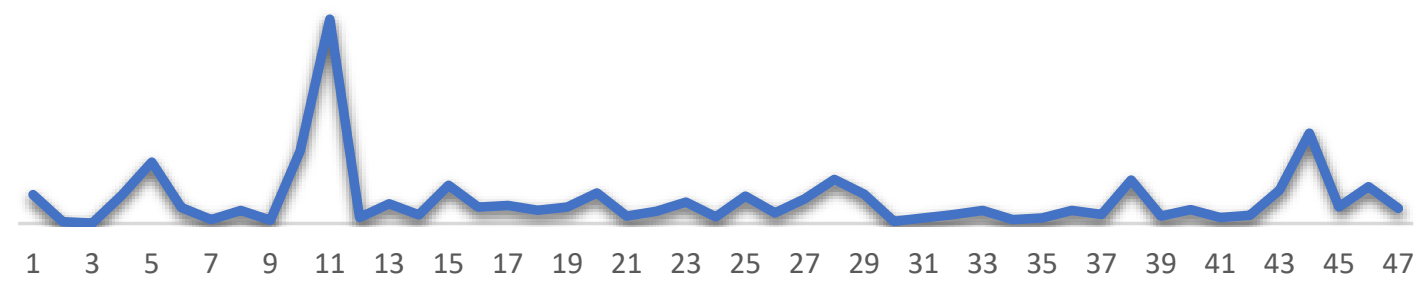

Source: Prepared by authors.

Regarding the total impact, considering now the direct and indirect effects of the disease in Input-Output Matrix of Brazil, given the influence of each sector in the economy, it was possible to measure the loss by productive segment to the year 2006, with the respective indicator of the Inoperability vector $(q)$, which reflects how much the demand of each sector has been degraded, varying from 0 to 1 , where 0 indicates that there is no sectoral loss at all, and 1 that the loss is $100 \%$, that is, the economy was totally compromised by the shock.

The sector that presented the greatest loss was the chemical and chemical products segment, indicated by sector 11 of the WIOD table, with a loss of US\$ $147,467,555.86$, with an impact of $0.229 \%$ in this sector, as measured by the vector $q$ of Inoperability. Sector 51, public administration, defense and social security, appears to have suffered the second largest impact, presenting a loss of US\$ $65,205,766.28$, with a $0.046 \%$. Sector 10 , corresponding to the manufacture of coke, petroleum products and biofuels, was the third most affected sector, with losses of US\$ 52,445,243.59, and with a $0.065 \%$. The sector that registered the lowest loss among those evaluated was the fishing and aquaculture segment, with a recorded loss of US\$ 316,023.04, with a $0.020 \%$ Inoperability vector.

The total impact on the Brazilian economic matrix, calculated from the Leontief Inverse concept, is given by the sum of the impacts in each sector analyzed, totaling, to 2006, the value of US\$ $807,108,399.94$.

Economic impact of ICDS in 2014

In 2014, taking into account the total expenditure by the government with the morbidity generated by Ischemic Heart Diseases, it can also be seen from Table 1 that these diseases were responsible for 253,834 , hospital admissions, with a stay in these hospitals quantified at 1,640,937 days, leading to a total cost of US\$ $437,551,501.27$ to the public coffers. Look to Figures 3 and 4.

Figure 3 - Salaries lost in 2014 from Ischemic Heart Diseases

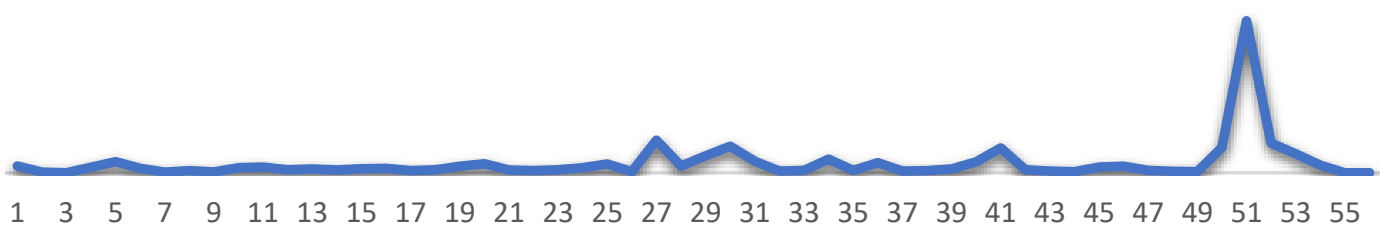

Source: Prepared by authors. 
Considering now the direct effects of Ischemic Cardiopathy on the Brazilian GDP, the impacts are measured based on the workers' wage loss. Sector 51, public administration, defense and social security, had the highest wage loss in 2014, with sums that reached US\$103,707,024.16. The second sector with the highest salary loss among the 56 evaluated was sector 27 , which concerns building construction activities, infrastructure works and specialized services for construction, with a loss of US\$ 22,232,882.99. Another segment that had a large salary loss from
Ischemic Heart Disease, appearing as the third most affected sector, was sector 52 (education activities), with salary suppression estimated at US\$ 20,248,789.50. Among the sectors evaluated, the segment that showed the least direct impact was the one related to domestic services, illustrated by the number 55 and with an impact of US\$ 7,945.96.

To the year 2014, the direct impact on GDP, measured in terms of wage losses, was estimated at US\$361,984,144.89. This value reflects the direct effect of the ICDs on workers in the 56 sectors analyzed.

Figure 4 - Economic loss, in US\$, by sector in 2014

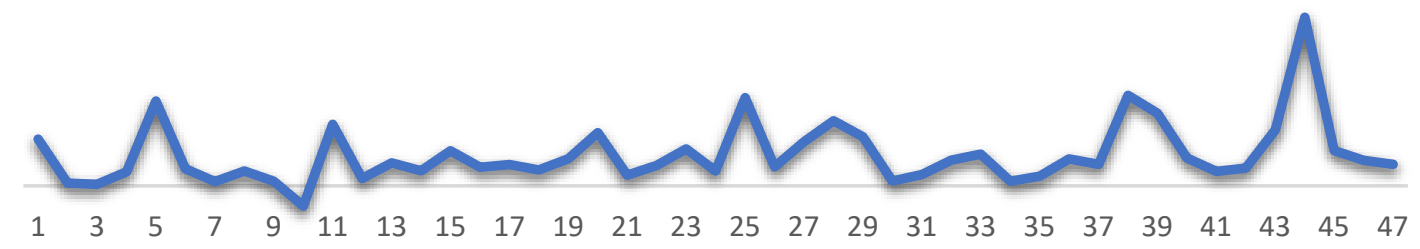

Source: Prepared by authors.

The economic impact by sector, which considers the economic loss or shock caused by IHD in each segment, was also measured for 2014, with the corresponding Inoperability vector of each area. The sphere most affected in 2014, as well as the one with the highest wage loss, was that of public administration, defense and social security (sector 51), with a record of US\$ 147,502,379.06, lost due to Ischemic Heart Diseases. The vector of inoperability of this sector was $0.050 \%$, this being its impact in percentage in the referred sector. Sector 41 , of financial services activities, is the second most impacted by the disease, with its loss valued at US\$ 79,132,284.74 and its vector $\mathrm{q}$ at $0.025 \%$. The construction segment, which covers building construction activities, infrastructure works and specialized services for construction, showed a loss of US\$ 77,112,855.16, representing this value $0.022 \%$ of the total produced by this sector in the economy. The sector with the lowest loss among those evaluated was the sector 3 , which deals with fishing and aquaculture activities, with losses of US\$ $1,334,694.94$ and a vector of normalized economic loss of $0.010 \%$.

The total impact in 2014, generated from DALYs caused by Coronary Artery Disease, was US\$ 1,297,819,879.47. This amount contemplates the total economic loss in the Input-Output Matrix of Brazil to the year under analysis, not considering the governmental expenditure coming from hospitalizations for these diseases. Comparison and sum of public expenditure with the total impact on the Brazilian InputOutput Matrix are carried out in the next section.

COMPARING THE IMPACT OF IHD: 2006 X 2014

Public expenditures related to hospital admissions for Ischemic Heart Diseases were quite significant both in 2006 and 2014. To the first period under review, 
total public expenditure on hospital admissions was US\$213,505,120.41. To 2014, the total expended by the Brazilian government was equal to US\$ 437,551,501.27. Look to Tables 2 and 3.

Table 2 - Data on morbidity due to IHD in SUS in 2006

\begin{tabular}{|lr|}
\hline Hospital admissions & 208,176 \\
\hline Days of stay & $1,340,793$ \\
\hline Total Government spending & US\$ $213,505,120.41$ \\
\hline Estimated population of Brazil & $183,987,291$ \\
\hline Ratio of hospitalizations by population & $0.113 \%$ \\
\hline
\end{tabular}

Source: Prepared by authors from SIH/SUS data.

Table 3 - Data on morbidity due to IHD in SUS in 2014

Hospital admissions

253,834

Days of stay

$1,640,937$

Total Government spending

Estimated population of Brazil

Ratio of hospitalizations by population
$1,640,937$

US\$ 437,551,501.27

$202,768,562$

$0.125 \%$

Source: Prepared by authors from SIH/SUS data.

Tables 2 and 3 show the impact of morbidity on SUS generated from hospitalizations for Ischemic Heart Diseases. In 2014 it is possible to observe that there is a larger portion of the population that was hospitalized for IHD than the total population when compared to the 2006 data, which suggests a greater influence as a cause of morbidity in that period in relation to this one.

Analyzing the impact of the IHDs on Input-Output Matrix of Brazil, it was observed that public administration, defense and social security sector, illustrated by number 51 of the table provided by WIOD, presented higher wage losses in both years, considerably from other sectors. The alarming figures of this sector are due to this being the segment that accommodated the largest number of workers in 2006, according to the ASIR data, with 8,673,795 people and was the second segment that had more workers in 2014, with $11,147,573$ people, behind retail trade for that year. Domestic service, sector 55, also for the years 2006 and 2014, presented lower salary losses, with amounts of US\$ 17,765.81 and US\$ 7,945.96, respectively.

Comparing the years 2006 and 2014, it could be noted that the sectors with the highest wage losses do not correspond to the sectors with the greatest economic losses. In the case of wages lost due to Ischemic Cardiopathy, there is a greater weight to the number of workers per sector and the remunerations received by them, measured in minimum wage amounts. To calculation of the economic loss, on the other hand, the determining factor is how much that sector produces for the country's economy and how much it is impacted by the IHD.

The direct impact on Input-Output Matrix in 2006, expressed in current values, was US\$ 165,903,042.64, which corresponded to $0.015 \%$ of the total Gross Domestic Product of that year. By 2014, the direct impact on GDP due to the incidence 
of Ischemic Heart Diseases, with its burden due to the impacts of deaths and morbidity caused (DALYs), was equal to $0.0147 \%$, totaling, in 2014, US\$ 361,984,144.89. It should be noted, however, that the year
2006 accounted to a sector more than the one of 2014, which was discarded by problems in its calculation, concerning the manufacture of coke, petroleum products and biofuels.

Chart 1 - Evolution of the sectors with the highest wage losses: 2006 - 2014

\begin{tabular}{|c|c|c|c|c|c|}
\hline Order & Sector & $\begin{array}{c}\text { \% Total of } \\
\text { the Impact }\end{array}$ & Order & Sector & $\begin{array}{c}\text { \% Total of } \\
\text { the Impact }\end{array}$ \\
\hline $1^{\circ}$ & 51 & $26,4 \%$ & $1^{\circ}$ & 51 & $28,6 \%$ \\
\hline $2^{\circ}$ & 53 & $8,2 \%$ & $2^{\circ}$ & 27 & $6,1 \%$ \\
\hline $3^{\circ}$ & 30 & $6,7 \%$ & $3^{\circ}$ & 52 & $5,6 \%$ \\
\hline $4^{\circ}$ & 50 & $6,0 \%$ & $4^{\circ}$ & 30 & $5,0 \%$ \\
\hline $5^{\circ}$ & 41 & $4,9 \%$ & $5^{\circ}$ & 50 & $4,8 \%$ \\
\hline $6^{\circ}$ & 52 & $4,4 \%$ & $6^{\circ}$ & 41 & $4,7 \%$ \\
\hline $7^{\circ}$ & 27 & $3,9 \%$ & $7^{\circ}$ & 53 & $3,6 \%$ \\
\hline $8^{\circ}$ & 29 & $2,7 \%$ & $8^{\circ}$ & 29 & $3,2 \%$ \\
\hline
\end{tabular}

Source: Prepared by authors.

In relation to the sectoral economic loss, in 2006 sector 51, refering to public administration and defense; compulsory social security was the first of the 47 evaluated, accounting for $26.4 \%$ of the total impact. The estimated value for sector 51 is approximately 3 times higher than that of the second most affected sector for the same year, which refers to segment 53, human health activities and social assistance, representing $8.2 \%$ of the total impact.

When the estimated values to 2014 were observed, the segment that came second in 2006, passed to seventh place as the sector that suffered the most economic losses (3.6\% of the total impact). Sector 27 , in terms of construction, was seventh in 2006 , with a total impact of $3.9 \%$ and in 2014 it rose to second place, representing a loss of $6.1 \%$ of the total impact. And sector 51 remained the most impacted sector, accounting for $28.6 \%$ of the total impact.

To both periods, the fishing and aquaculture sector was the least affected by Ischemic Heart Diseases in economic terms, presenting values of US\$ $316,023.04$ in
2006 and US\$ 1,334,694.94 in 2014. Through the estimations, it was possible to observe that the Inoperability vector of one sector does not necessarily entail greater economic loss when compared to a vector of another sector, which means that there may be a segment with less $q$, but that leads to greater loss than a second segment with a larger $q$ vector. This situation occurs because the sectors are impacted in different ways by the IHD and also because they have different degrees of influence in the economy, in which there are sectors more and less economically productive.

The sector with the largest vector of Inoperability in 2006 coincided with the sector with the greatest economic loss, with sector 11 presenting $0.229 \%$. In 2014, the segment most impacted in this same issue was segment 33, related to activities related to air transportation, with an indicator of $0.0614 \%$. Inoperability of Input-Output model illustrates the degree of destruction of the economy, showing the compromised percentage of each sector due to IHD. 
Figure 5 - Percentage of degradation by economic sector in 2006

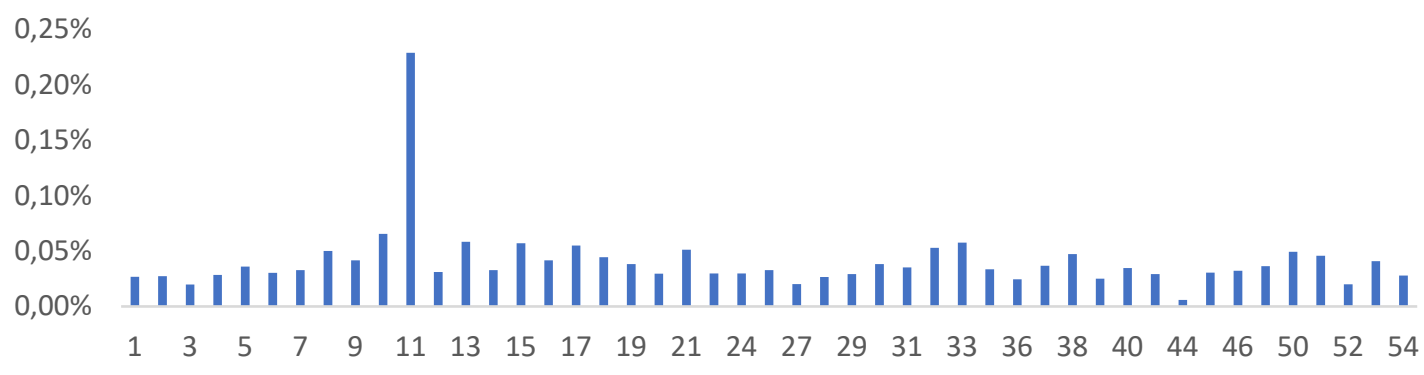

Source: Prepared by authors.

In 2006, sector 11 was reached to a much greater degree when compared to the other 46 sectors under analysis, being compromised in more than two and a half times that the second most affected sector, related to the manufacture of coke, petroleum products and of biofuels, with $0.065 \%$ inoperability vector for that same year.

Figure 6 - Percentage of degradation by economic sector in 2014

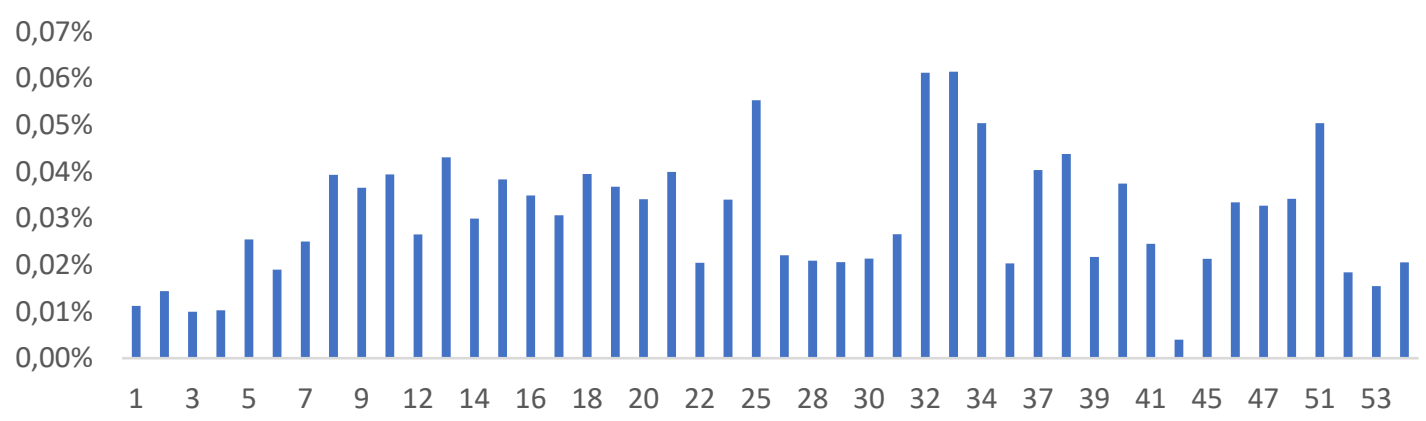

Source: Prepared by authors.

In 2014, none of the Inoperability vectors presented an incidence above $0.062 \%$, there was no disparity as evidenced in 2006, and also in 2014 there were five sectors with incidences above $0.05 \%$. The total impacts, measured as the direct and indirect impacts on Input-Output Matrix of Brazil, could be estimated from Leontief Inverse Matrix concept, which provides information on how sectors can be affected and affect the economy in a direct and indirect. In 2006, the total impact was US\$ $807,108,399.94$, which is equivalent to $0.073 \%$ of GDP. In 2014, this impact was estimated at US\$ 1,297,819,879.47, corresponding to $0.053 \%$ of GDP.

Adding the direct and indirect impacts to government spending, it is possible to have the perspective of the total reach of Ischemic Cardiopathy in Brazil. The year 2006 had a total impact of US\$
$807,108,399.94$ in Input-Output Matrix and the government spent US\$213,505,120.41, totaling an impact in Brazilian economy of US\$ 1,020,613,520.25, equivalent to $0.092 \%$ of GDP. To 2014, direct and indirect expenses Input-Output Matrix resulted in a loss of US\$ $1,297,819,879.47$, and the Brazilian government spent the total of US\$ 437,551,501.27, where the total impacts were US\$ 1,735,371,372.25, representing a total of $0.071 \%$ of GDP.

\section{CONCLUSIONS}

The understanding of the impacts of diseases and health problems on society and economy of a country is useful in order to allow a planning in line with the real influence of these pathologies in population, in order to be able to define the priorities to the government spending on 
public health. The economic analysis of these impacts, therefore, has the character of providing intelligible information and subsidizing research and policies in the field of health.

Through the results obtained, it was observed that the sector of public administration, defense and social security, to both period 2006 and 2014, was shown to be the sector that suffered the most losses, with estimated values of US\$ 43 million in 2006 and a little more than US\$ 103 million in 2014. These values can be explained by that sector being one of the two that most accommodated workers in both periods. Measured through the sum of wages lost as a result of abstention to work due to Ischemic Heart Diseases, the direct impact on GDP in 2006 was US\$ 165,903,042.64 and in 2014 the value found was equal to US\$ $361,984,144.89$. To the two years studied, the direct impact turned around $0.015 \%$ of GDP to each year and the results were presented in current values.

To the loss per sector, the segment that presented the largest suppression of its production in 2006 was related to the manufacture of chemicals and chemical products, being affected by a loss in excess of US\$ 147.1 million. The total impact on GDP, which considers the direct and indirect effects of IHD in Input-Output Matrix, was US\$ 807,108,399.94. In 2014, as well as having registered the largest wage loss, the sector related to public administration, defense and social security activities recorded the largest loss in its production, with values estimated at more than US\$ 147.4 million. To the same year, the total impact on Brazilian Input-Output Matrix was equal to US\$ 1,297,819,879.47.

Although in 2006 the sector with the greatest economic loss coincided with the one with the greatest degradation of its product, the results showed that the Inoperability vectors, do not accompany the sectors with the greatest economic losses. It occurs due to the productive sectors influencing in different ways the total produced by the economy, with sectors more productive than others, besides the fact that there are sectors with workers in conditions more susceptible to the affection of Ischemic Cardiopathy.

The impact on Brazilian economy in general, considering the effects on InputOutput Matrix and government expenditures with Ischemic Cardiopathy, was US\$ $1,020,613,520.25$ in 2006, equivalent to $0.092 \%$ of GDP and US\$ $1,735,371,372.25$ in 2014, representing $0.071 \%$ of GDP. About research limitation reside in database. To avoid using proxy, is necessary get more and much better information about patients, such as: profession, sector in which it works, salary, time of hospitalization, absence time at work.

\section{REFERENCES}

COSTA, C. C.; GUILHOTO, J. J. M. Rural sanitation in Brazil: impact of the septic tank biodigestor", Sanitary and Environmental Engineering, v. 19, n. 1, p. 51-60, 2014.

\section{DATASUS. I20-I25 Ischemic heart}

disease - 2008. Available at:

http://www.datasus.gov.br/cid10/V2008/W ebHelp/i20_i25.htm. Accessed on: 12 sep. 2018.

DRUMMOND M. E.; SCULPHER M. J.; TORRANCE G. W. Methods for the economic evaluation of health careprogrammes, $3^{\text {rd }}$ ed, Oxford University Press, 2005, Journal of Epidemiology \& Community Health, v. 60 , n. 9, p. 822823, 2006.

FONSECA, R. H. A.; PEDROSO, J. M. A.; PINTO, J. A. Jr.; SOUZA e SILVA, N. A.; GAMERMAN, D.; DUARTE, M. M. T. Spatial analysis of cerebrovascular mortality in Rio de Janeiro municipality from 2002 to 2007, demographic and socioeconomic correlations. European 
Heart Journal, v. 34, n. 1, p. 2500-2500, 2013.

GUILHOTO, J. J. M. Leontief and inputoutput: background, principles and evolution, MPRA Paper, v. 54649, n. 21, p. 1-44, 2001.

HAIMES, Y. Y.; JING, P. Leontief-Based model of risk in complex interconnected infrastructures, Journal of Infrastructure Systems, v. 7, n. 1, p. 1-12, 2001.

IBGE - Brazilian Institute of Geography and Statistics. Projection of the population of Brazil and of the Federation Units - 2017. Available at: https://www.ibge.gov.br/apps/populacao. Accessed on: 29 Aug. 2018.

IHME - Institute for Health Metrics and Evaluation (2013; 2017; 2018). Available at: http://www.healthdata.org. Accessed on: 18 Jan. 2018.

LEITE, I. C.; VALENTE, J. G.; SCHRAMM, J. M. A.; DAUMAS, R. P.; RODRIGUES, R. N.; SANTOS, M. F.; OLIVEIRA, A. F.; SILVA, R. S.; CAMPOS, M. R.; MOTA, J. C. Burden of disease in Brazil and its regions, 2008.

Public Health Notebook, v. 31, n. 7, p. 113, 2015.

LEONTIEF, W. The Structure of American Economy, 1919-39, New York: Oxford University Press, 1951.

LEUNG, M.; HAIMES, Y. Y.; SANTOS, J. R. Supply and output-side extensions to the inoperability input-output model for interdependent infrastructures, Journal of Infrastructure Systems, v. 13, n. 4, p. 299-310, 2007.

MACHADO, A. M. O. Chronic diseases, Brazilian Journal of Pathology and Laboratory Medicine, v. 42, n. 1, p. 1-1, 2006.
MARCONI, N.; ROCHA, I. L.;

MAGACHO, G. R. Sectoral capabilities and productive structure: an input-output analysis of the key sectors of the Brazilian economy, Policy Economic Journal, v. 36, n. 3, p. 470-492, 2016.

MARINHO, F.; PASSOS, V. M. A.; FRANÇA, E. B. New century, new challenges: changes in the burden of disease profile in Brazil, 1990-2010, Epidemiology and Health Services Journal, v. 25, n. 4, p. 713-724, 2016.

MILLER, R. E.; BLAIR, P. D. InputOutput analysis: foundations and extensions, Cambridge University Press, 2nd edition, New York, 2009.

MURRAY, C. J. L.; LOPEZ, A. D. The global burden of disease, published by the Harvard School of Public Health on Behalf of the World Health Organization and the World Bank distributed by Harvard University Press, 1996.

NCI - National Cancer Institute. Household Survey on Risk Behaviors and Referred Morbidity of Noncommunicable Diseases and Diseases - 2004, Brazil, 15 capitals and Federal District 2002-2003. Available at: http://www.inca.gov.br/inquerito/docs/isqu emicas coracao.pdf. Accessed on: $04 \mathrm{Jul}$. 2018.

NHS - National Health Survey. Rio de Janeiro: Brazilian Institute of Geography and Statistics - IBGE, 20132014. Available at: http://ftp://ftp.ibge.gov.br/PNS/2013/pns20 13.pdf. Accessed on: 01 Aug. 2018.

PAHO - Pan American Health Organization. Cardiovascular diseases 2017. Available at: https://www.paho.org/bra/index.php?optio $\mathrm{n}=\mathrm{com} \_$content\&view $=$article $\& \mathrm{id}=5253: \mathrm{do}$ encas-cardiovasculares \&Itemid $=1096$. Accessed on: 27 Jun. 2019. 
RASMUSSEN, B.; SWEENY, K.; SHEEHAN, P. Economic costs of absenteeism, presenteeism and early retirement due to III health: a focus on Brazil. Victoria Institute of Strategic Economic Studies Victoria University: Melbourne, 2015.

SANTOS, J. R. An input-output framework for assessing disaster impacts on Nashville metropolitan region, 20th

IIOA conference in Bratislava, 2012.

SANTOS, J. R.; HAIMES, Y. Y. Modeling the demand reduction input-output (I-O) inoperability due to terrorism of interconnected infrastructures, Risk Analysis, v. 24, n. 6, p. 1437-1451, 2004.

SCHMIDT, M. I.; DUNCAN, B.B.; E SILVA, G. A.; MENEZES, A. M.; MONTEIRO, C. A.; BARRETO, S. M.; CHOR, D.; MENEZES, P. R. Chronic noncommunicable diseases in Brazil: current burden and challenges, The Lancet, v. 377, n. 9781, p. 1949-1961, 2011.

SIH/SUS - System Information Health: Information Technology at the SUS
Service (2018). Available at:

http://tabnet.datasus.gov.br/cgi/deftohtm.e xe?sim/cnv/obt10uf.def. Accessed on: 06 Jul. 2018.

SIQUEIRA, A. de SÁ, E.; SIQUEIRAFILHO, A. G.; LAND, M. G. P. Analysis of the economic impact of cardiovascular diseases in the last five years in Brazil. Brazilian Archives of Cardiology, v. 109, n. 1, p. 39-46, 2017.

TAKASAGO, M.; GUILHOTO, J. J. M.; MOLLO, M. L. R.; DE ANDRADE, J. P. The potential creator of employment and income of tourism in Brazil, Research and Economic Planning, v. 40, n. 3, p. 439468, 2017.

TOWNSEND, N.; NICHOLS, M.; SCARBOROUGH, P.; RAYNER, M. Cardiovascular disease in Europe epidemiological update 2015, European Heart Journal, v. 36, n. 40, p. 2696-2705, 2015.

TURA, B. R.; SILVA, N. A. S.; PEREIRA, B. B. Association between per capita income and mortality by cardiovascular disease, SOCERJ Journal, v. 4, n. 1, p. 215-218, 2006.

\section{${ }^{1}$ Henry Ledur Paz Cezar}

Graduado em Ciências Econômicas pela Universidade Federal Rural do Rio de Janeiro (UFRRJ) e Diretor Administrativo do Instituto do Coração Edson Saad da Universidade Federal do Rio de Janeiro (UFRJ)

\footnotetext{
${ }^{2}$ Everlam Elias Montibeler

Doutor em Economia Aplicada pela Universidade Complutense de Madri - UCM e Professor Associado I do Departamento de Economia e do Programa de Pós-Graduação em Economia Regional e Desenvolvimento (PPGER) da Universidade Federal do Rio de Janeiro - UFRRJ

\section{${ }^{3}$ Daniel Rodrigues Cordeiro}

Mestre em Administração pela Universidade Federal Rural do Rio de Janeiro - UFRRJ e Membro do Núcleo de Estudos Avançados em Finanças (NEAF)
} 